\title{
Effect of various kenaf fiber content on the mechanical properties of composites
}

\author{
F.A. Fauzi $^{1 *}$, Z. Ghazalli ${ }^{1}$ and J.P. Siregar ${ }^{1}$ \\ ${ }^{1}$ Faculty of Mechanical Engineering, Universiti Malaysia Pahang, \\ 26600 Pekan, Pahang, Malaysia, "Email: farahayunifauzi@gmail.com \\ *Phone: +60136394126; Fax: +6094246222
}

\begin{abstract}
Kenaf fiber has been cultivated as an industrial crop. In this paper, we present the ongoing works of an assessment on the mechanical properties of its fiber composites. Tensile, flexural and impact tests were executed on untreated short kenaf fiber reinforced epoxy composites. Its fiber content is varied from $5 \%$ up to $20 \%$, and was compared to neat epoxy (NEAT). Using a hand lay-up technique, a mixture of kenaf fiber and epoxy is poured into a mould and left to dry at room temperature for 24 hours. Seven specimens were cut according to ASTM D3039, ASTM D790 and ASTM D256 for the tensile test, flexural test and impact test, respectively. The results showed that the tensile, flexural and impact strengths of the kenaf fiber are lower compared to NEAT. Samples at 5\% kenaf fiber content shows the highest tensile strength, flexural strength and impact strength at 27. $1 \mathrm{MPa}$ and $18.2 \mathrm{MPa}$ and $0.56 \mathrm{~kJ} / \mathrm{m} 2$, respectively. The $5 \%$ fiber content was finalized as the fiber content that can be applied in archery.
\end{abstract}

Keywords: Short kenaf fiber; tensile test; flexural test; impact test; hand lay-up technique

\section{INTRODUCTION}

Kenaf fibers (Hibiscus cannabinus, L. family Malvaceae) are widely used because it has been appraised as environmentally advantageous and has high commercial interests [1]. Kenaf fiber reinforced polymer is reported to have better mechanical strength and thermal properties compared to other bast fiber reinforced polymer [1-5]. However, there is a need for a study on various kenaf fiber content for utilization in sports equipment. Reinforcement of kenaf fiber with polymers such as the reinforcement of kenaf with unsaturated polyester, kenaf with polypropylene and kenaf reinforced epoxy have been widely presented by researchers [6-11]. Nonetheless, the usage of kenaf fiber for various applications such as in the automotive, construction and sports fields have only started to get the attention of many researchers, and the trend is increasing according to market demand $[12,13]$. A study on the effect of various kenaf fiber content on its mechanical properties may increase the demand of kenaf fibers, especially in Malaysia.

The use of kenaf fiber has surprisingly increased worldwide due to its contribution to the development of eco-friendly material in automotive, sports application and food packaging fields $[1,14]$. Many researchers have presented work related to the properties of kenaf fiber composites. Khalil et al. [15] studied the basic characteristics and physical properties of kenaf fiber. Salleh et al. [16] examined the effect of water absorption on long kenaf hybrid woven glass using the cold press technique. The study showed that deterioration of composite occurs due to the presence of liquid. Improvement in the mechanical properties of natural fiber composites may be obtained through the 
hybridization of natural fiber with glass fiber [17]. Davoodi et al. [18] reported that kenaf/glass fiber produces similar tensile strength, Young's modulus, flexural strength and flexural modulus with glass mat thermoplastic (GMT), the material used for car bumper manufacturing.

The objective of this paper is to determine the effect of various fiber content of kenaf fiber on the mechanical properties of its composites. A thorough study on the mechanical behavior of untreated kenaf fiber composites in terms of tensile, flexural and impact is discussed in this section. This paper presents the experimental set-up of the composite materials and its respective mechanical testing. Results of the mechanical behavior on kenaf fiber are discussed in the next section. Finally, the study is concluded in the last section of this paper.

\section{EXPERIMENTAL SET UP}

\section{Materials}

Short kenaf fibers with the density $1.2 \mathrm{~g} / \mathrm{cm}^{3}$ were used for this study. Epoxy DER 331 and Jointmine 905-3 were chosen for matrix and hardener, respectively. The resin and hardener were mixed in a ratio of 2:1. Five formulations of volume fractions were used for the composite, which are $0 \%$ (NEAT), $5 \%, 10 \%, 15 \%$ and $20 \%$ short kenaf fiber.

\section{Preparation of Composite Material}

A hand lay-up technique was used during the fabrication of the natural fiber composites. The natural fiber composites were made up using a glass mould with dimensions of 200 $\mathrm{mm} \times 200 \mathrm{~mm} \times 3 \mathrm{~mm}$. Figure 1 shows the illustration of the hand lay-up technique used to prepare the samples. The mixture of the kenaf fiber and epoxy resin with hardener was poured gently on the glass mould to ensure that no air bubbles were trapped. A plastic cover was placed on the semi-solid kenaf fiber reinforced epoxy. The function of the plastic cover is to reduce the presence of bubbles at the surface of the natural fiber composite. The composites were left at room temperature for 24 hours to let it harden. After the composites hardened, they were cut according to ASTM standards as depicted in Figure 2. For NEAT, the samples were prepared using the same procedures as the natural fiber composites, but without the addition of kenaf fiber.

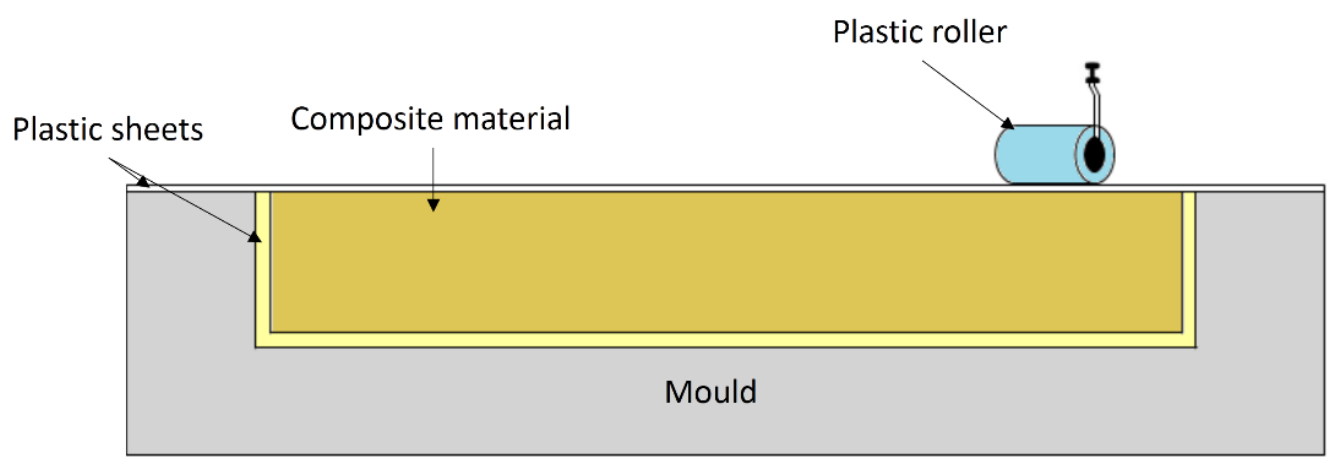

Figure 1. Hand lay-up technique. 


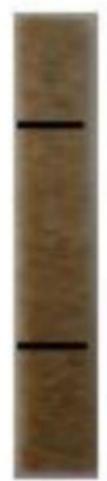

(a)

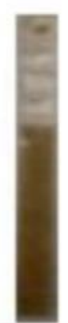

(b)

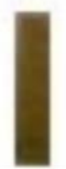

(c)

Figure 2. Sample of natural fiber composites according to ASTM Standards; (a) Tensile test (ASTM D3039), (b) Flexural test (ASTM D790), (c) Impact test (ASTM D256).

\section{Mechanical Testing}

Tensile and flexural tests were respectively performed according to ASTM D3039 and ASTM D790 standards using a universal tensile testing machine INSTRON model with a maximum load of 50kN $[19,20]$. For the flexural test, the crosshead speed and span-todepth ratio were set up to $1 \mathrm{~mm} / \mathrm{min}$ and 16:1, respectively. Seven specimens from each condition were used for both types of tests. The flexural average and flexural modulus were calculated. An impact test was conducted on the seven specimens of each condition using the Charpy impact test. The impact tests were performed using Zwick Roell with a maximum impact energy of $50 \mathrm{~J}$. The procedures for this test followed ASTM D256 at room temperature [21]. The impact energy and impact strength values were obtained from the testing. The impact strength obtained from calculations suggested by $[22,23]$ is shown in Eq. (1):

$$
\text { Impact strength }\left(\mathrm{kJ} / \mathrm{m}^{2}\right)=\frac{\operatorname{Impact} \operatorname{energy}(\mathrm{J})}{\text { Cross sectional } \operatorname{area}\left(\mathrm{m}^{2}\right)} \times \frac{1}{10^{3}}
$$

\section{RESULTS AND DISCUSSION}

The effect of volume fraction on the mechanical properties of kenaf fiber will be addressed in the next sub-section. The mechanical properties involved in this study are tensile, flexural and impact properties.

\section{Tensile Properties of Kenaf/Epoxy Composites}

The effects of volume fraction on tensile modulus and tensile strength are shown in Figure 3 and 4, respectively. These results show that 5\%,10\%,15\% and 20\% untreated kenaf fiber have slightly lower tensile modulus compared to NEAT epoxy (see Figure 3). It can be noted that the addition of kenaf fiber decreases the tensile modulus. This is because the increment of kenaf fiber content in composite material reduces the interfacial bonding between epoxy and kenaf fiber. This results supports the finding by Davoodi et al. [18] who found that the tensile modulus of composite materials increased due to the strong adhesion between the matrix and its reinforcement. Figure 4 shows the huge difference of tensile strengths between NEAT and 5\%, 10\%, 15\% and 20\% kenaf fiber. 
Still, as the kenaf fiber increases, the strength of the composites decreases. One possible explanation is that the addition of random natural fiber in epoxy does not fully reinforce the matrix. This result is in agreement with Monteiro et al. [24]. However, a few studies have shown contrary results, claiming that the strength of natural fiber composites increases as the volume content of natural fiber increases [25].

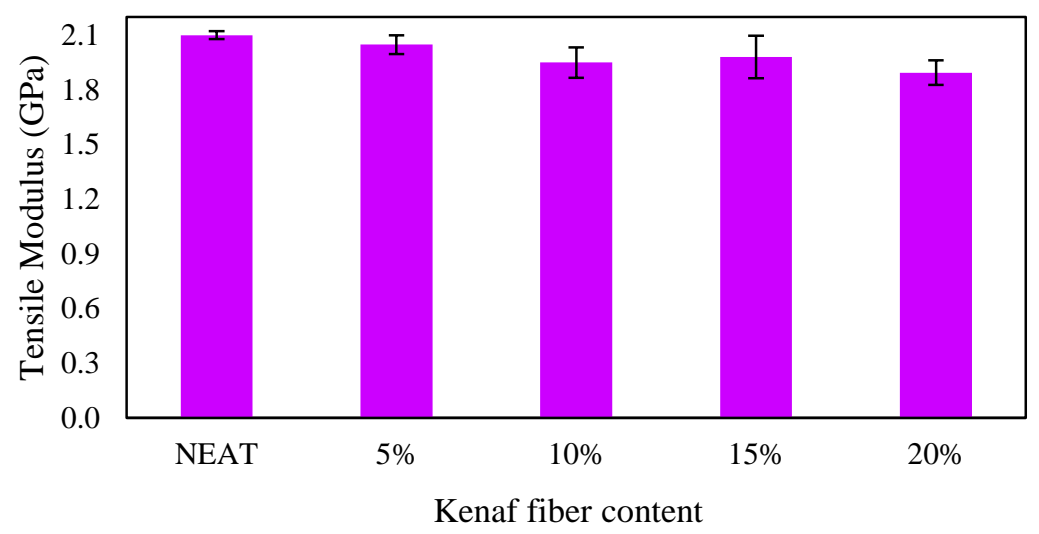

Figure 3. Effect of various kenaf fiber content on tensile modulus.

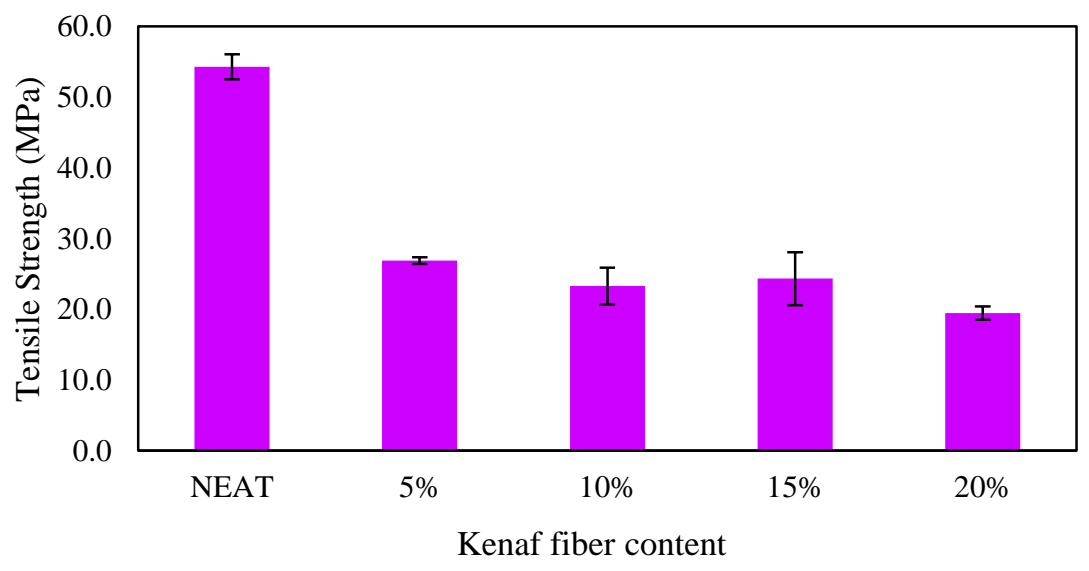

Figure 4. Effect of various kenaf fiber content on tensile strength.

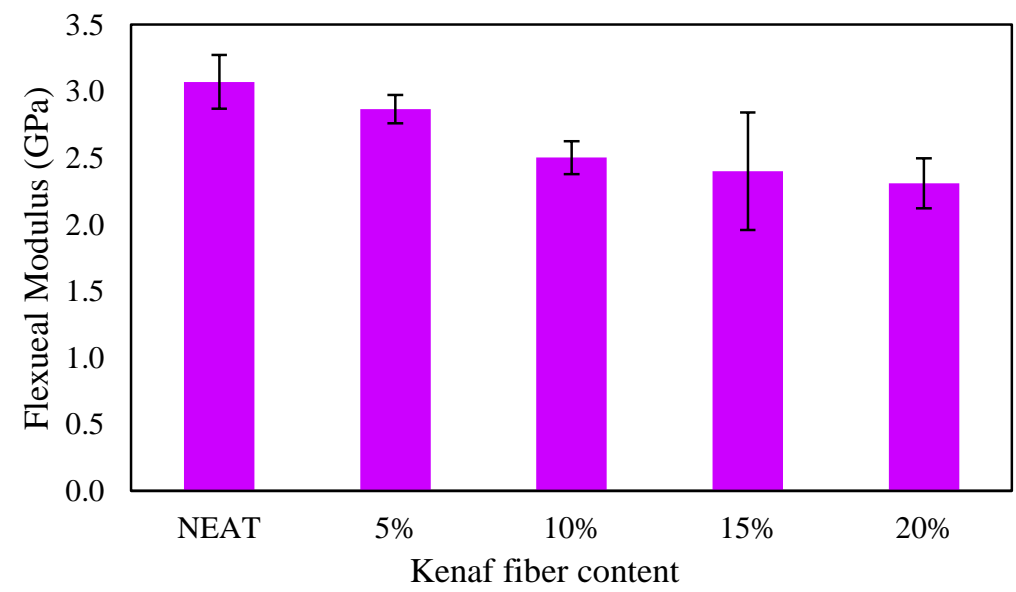

Figure 5. Effect of various kenaf fiber content on flexural modulus. 


\section{Flexural Properties of Kenaf/Epoxy Composites}

The flexural modulus and flexural strengths of NEAT and untreated kenaf fiber reinforced epoxy are shown in Figure 5 and 6, respectively. The 5\% kenaf/epoxy composite have the closest flexural modulus value with NEAT. The flexural modulus value was reduced $7.05 \%$ when $5 \%$ kenaf fiber was added. Meanwhile, the flexural strength for all fibers show obviously lower values when compared to NEAT. The difference of NEAT with $20 \%$ kenaf fiber is $62.48 \%$. The reason is that an increase of fibre loading leads to the agglomeration of natural fibre in the composite materials. This could cause the stress transfer to the fibre gets blocked and reduces the performance of flexural modulus and flexural strength $[26,27]$.

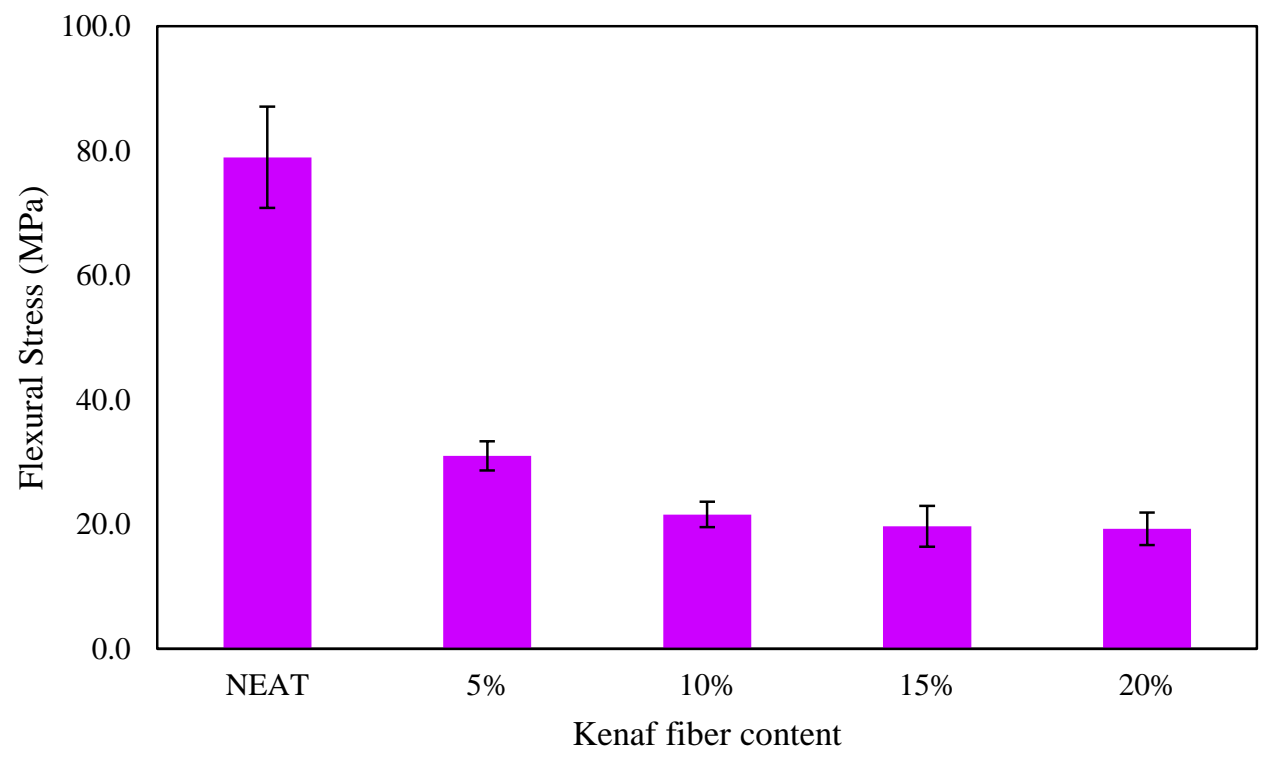

Figure 6. Effect of various kenaf fiber content on flexural strength.

\section{Impact Properties of Kenaf/Epoxy Composites}

Figure 7 and 8 show the effect of kenaf fiber fraction on impact energy and impact strength. Impact energy is the highest at $10 \%$ kenaf fiber content and impact strength is the highest at 5\% kenaf fiber content. However, in Figure 7 and 8 as compared to NEAT, they both have extremely lower values. This is contrary to normal expectations that impact strength increases as kenaf fiber content increases, such as shown by Shanmugam and Thiruchitrambalam [28]. The data variation could be due to poor interfacial adhesion between the fiber and the matrix. This can be explained by the fact that natural fiber is hydrophilic in nature, while the matrix is hydrophobic in nature. This results support the findings of Narendar et al. [29] who proved this statement using scanning electron microscope (SEM) images of hybrid coir pith and nylon fabric reinforced epoxy. 


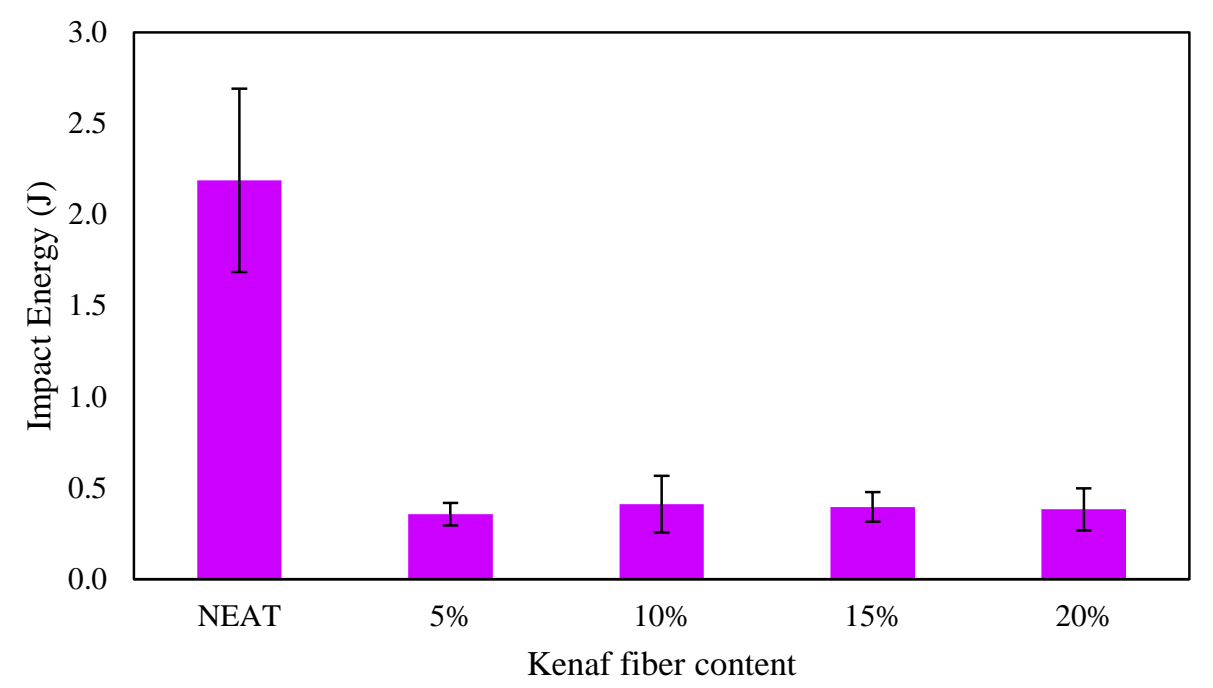

Figure 7. Effect of various kenaf fiber content on impact energy.

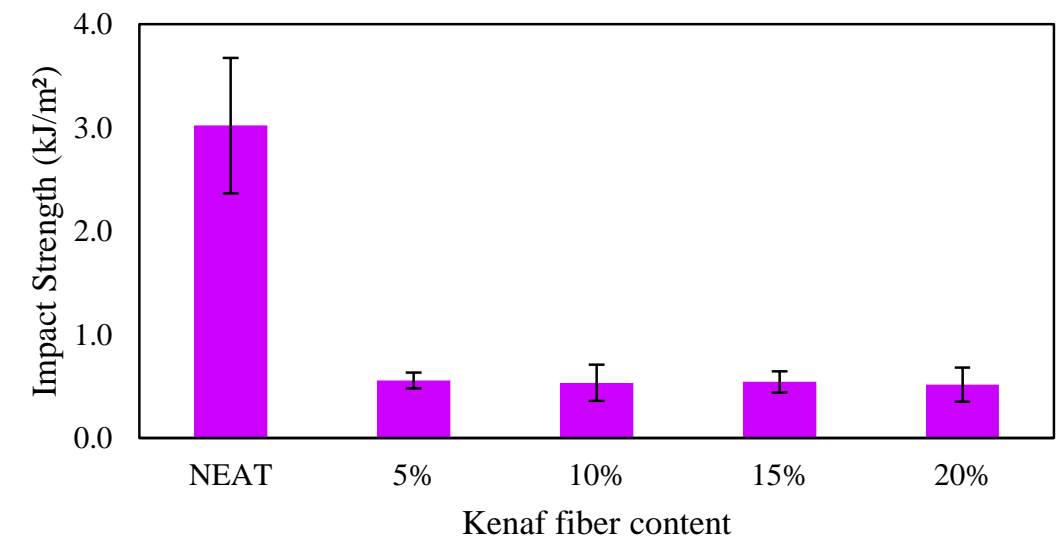

Figure 8. Effect of various kenaf fiber content on impact strength.

\section{CONCLUSIONS}

The effects of various kenaf fiber content on the mechanical properties of composite materials were investigated. The results revealed that tensile strength, flexural strength and impact strength of kenaf/epoxy composites are highest at 5\% volume fraction of kenaf fiber. 5\% volume fraction of kenaf fiber exhibits the highest tensile modulus and flexural modulus in its composite materials. Meanwhile, impact energy is highest at $10 \%$ kenaf fiber content. However, the randomly oriented kenaf fiber reinforced composites produced lower mechanical strength compared to NEAT epoxy. Despite that, a short fiber receives attention as it provides simple manufacturing procedures. The optimum strength of short kenaf fiber differs for each fiber content as the fiber distribution is different. Further study needs to be conducted on the development of natural fiber composites for usage in various applications i.e sports equipment as it is reported to have exceedingly low production compared to the automotive and construction fields. This is important if new improved material can be produced to reduce the usage of synthetic fiber. 


\section{ACKNOWLEDGEMENTS}

The author would like to thanks Universiti Malaysia Pahang for the equipment provided and Ministry of Science and Technology for financial support under the E-Science grant (RDU 140502).

\section{REFERENCES}

[1] Saba N, Paridah M, Jawaid M. Mechanical properties of kenaf fibre reinforced polymer composite: A review. Construction and Building Materials. 2015;76:8796.

[2] Nishino T, Hirao K, Kotera M, Nakamae K, Inagaki H. Kenaf reinforced biodegradable composite. Composite Science and Technology. 2003;63:1281-6.

[3] Fairuz AM, Sapuan SM, Zainudin ES, Jaafar CNA. Effect of filler loading on mechanical properties of pultruded kenaf fibre reinforced vinyl ester composites. Journal of Mechanical Engineering and Sciences. 2016;10:1931-42.

[4] Ismail AE, Che Abdul Aziz MA. Tensile strength of woven yarn kenaf fiber reinforced polyester composites. Journal of Mechanical Engineering and Sciences. 2015;9:1695-704.

[5] Umar AH, Zainudin ES, Sapuan SM. Effect of Accelerated Weathering on Tensile Properties of Kenaf Reinforced High-Density Polyethylene Composites. Journal of Mechanical Engineering and Sciences. 2012;2:198-205.

[6] Rashdi AAA, Salit MS, Abdan K, Ahmad M, Hamdan MM. Water absorption behaviour of kenaf reinforced unsaturated polyester composites and its influence on their mechanical properties. Pertanika Journal of Science \& Technology. 2010;18:433-40.

[7] Ishak MR, Leman Z, Sapuan S, Edeerozey A, Othman IS. Mechanical properties of kenaf bast and core fibre reinforced unsaturated polyester composites. IOP Conference Series: Materials Science and Engineering: IOP Publishing; 2010. p. 012006.

[8] Hao A, Zhao H, Jiang W, Yuan L, Chen JY. Mechanical properties of kenaf/polypropylene nonwoven composites. Journal of Polymers and the Environment. 2012;20:959-66.

[9] Abdullah AH, Khalina A, Ali A. Effects of Fiber Volume Fraction on Unidirectional Kenaf/Epoxy Composites: The Transition Region. PolymerPlastics Technology and Engineering. 2011;50:1362-6.

[10] Azwa ZN, Yousif BF. Characteristics of kenaf fibre/epoxy composites subjected to thermal degradation. Polymer Degradation and Stability. 2013;98:2752-9.

[11] Yousif BF, Shalwan A, Chin CW, Ming KC. Flexural properties of treated and untreated kenaf/epoxy composites. Materials \& Design. 2012;40:378-85.

[12] Papadopoulou E, Koundouras S, Stathopoulos C, Bikiaris D, Chrissafis K. Valueadded industrial products from fiber crops. Greece: In C. H. S.A. (Ed.); 2013.

[13] Brief L. Opportunities in Natural Fiber Composites. Lucintel; 2011.

[14] Anuar H, Zuraida A. Improvement in mechanical properties of reinforced thermoplastic elastomer composite with kenaf bast fibre. Composites Part B: Engineering. 2011;42:462-5. 
[15] Khalil HA, Yusra AI, Bhat A, Jawaid M. Cell wall ultrastructure, anatomy, lignin distribution, and chemical composition of Malaysian cultivated kenaf fiber. Industrial Crops and Products. 2010;31:113-21.

[16] Salleh Z, Taib Y, Hyie KM, Mihat M, Berhan M, Ghani M. Fracture toughness investigation on long kenaf/woven glass hybrid composite due to water absorption effect. Procedia Engineering. 2012;41:1667-73.

[17] Cicero JA, Dorgan JR, Dec SF, Knauss DM. Phosphite stabilization effects on two-step melt-spun fibers of polylactide. Polymer Degradation and Stability. 2002;78:95-105.

[18] Davoodi M, Sapuan S, Ahmad D, Ali A, Khalina A, Jonoobi M. Mechanical properties of hybrid kenaf/glass reinforced epoxy composite for passenger car bumper beam. Materials \& Design. 2010;31:4927-32.

[19] International A. ASTM D 3039. Standard Test Method for Tensile Properties of Polymer Matrix Composite Materials United States: American Society of Testing and Material; 2000.

[20] International A. ASTM D 790. Standard Test Methods for Flexural Properties of Unreinforced and Reinforced Plastics and Electrical Insulating Materials. United States: American Society of Testing and Material; 2003.

[21] International A. ASTM D 256. Standard Test Methods for Determining the Izod Pendulum Impact Resistance of Plastics. United States: American Society of Testing and Material; 2004.

[22] Aziz S, Ansell M, Clarke S, Panteny S. Modified polyester resins for natural fibre composites. Composite Science and Technology. 2005;65:525-35.

[23] Jayabal S, Velumani S, Navaneethakrishnan P, Palanikumar K. Mechanical and machinability behaviors of woven coir fiber-reinforced polyester composite. Fibers and Polymers. 2013;14:1505-14.

[24] Monteiro SN, Terrones LAH, D'Almeida JRM. Mechanical performance of coir fiber/polyester composites. Polymer Testing. 2008;27:591-5.

[25] Kasim AN, Selamat MZ, Daud MAM, Yaakob MY, Putra A, Sivakumar D. Mechanical properties of polypropylene composites reinforced with alkaline treated pineapple leaf fibre from Josapine cultivar. International Journal of Automotive and Mechanical Engineering. 2016;13:3157-67.

[26] Öztürk S. Effect of fibre loading on the mechanical properties of kenaf and fiberfrax fibre-reinforced phenol-formaldehyde composites. Journal of Composite Materials. 2010;44(19):1-10.

[27] Jacob M, Thomas S, Varughese KT. Mechanical properties of sisal/oil palm hybrid fiber reinforced natural rubber composites. Composite Science and Technology. 2004;64:955-65.

[28] Shanmugam D, Thiruchitrambalam M. Static and dynamic mechanical properties of alkali treated unidirectional continuous Palmyra Palm Leaf Stalk Fiber/jute fiber reinforced hybrid polyester composites. Materials \& Design. 2013;50:53342.

[29] Narendar R, Priya Dasan K, Nair M. Development of coir pith/nylon fabric/epoxy hybrid composites: Mechanical and ageing studies. Materials \& Design. 2014;54:644-51. 